\title{
Antioxidant and Bacteriostatic Effects of the Addition of Extract of Quillay Polyphenols (Quillaja saponaria) in the Marinade of Broiler Chicken
}

Technical Note

\section{Euthor(s)}

Fellenberg MA

Espinoza A

Peña I

Alarcón J

Departamento de Ciencias Animales Facultad de Agronomía e Ingeniería Forestal Pontificia Universidad Católica de Chile

\author{
Mail Adress \\ MA Fellenberg \\ Departamento de Ciencias Animales \\ Facultad de Agronomía e Ingeniería Forestal \\ Pontificia Universidad Católica de Chile \\ Av. Vicuña Mackenna 4860 \\ Macul \\ Santiago, Chile \\ E-Mail: mafellen@uc.cl
}

\section{Keywords}

Broiler meat, lipid oxidation, marinade, polyphenols, quillay.

This research was supported by the Foundation COPEC UC SC0003.

\begin{abstract}
The nutritional and sensorial characteristics of chicken meat can be affected by oxidative rancidity, process of oxidation of lipids in the meat that constitutes one of the main forms of food deterioration. This problem may be prevented or reduced by adding antioxidants to the meat during the process of marination. In the present study, the addition of a polyphenol-rich quillay extract (QLPerm ${ }^{\circledR}$ ) at 5 levels $(0,0.05,0.10,0.15$, and $0.20 \%)$ to the marinade of chicken meat was evaluated. The marinated meat was stored under refrigeration (6 ${ }^{\circ} \mathrm{C}$ ) for $0,2,4,6$, and 8 days. Basal and induced lipid oxidation was evaluated by TBARS analysis. Microbiological quality was assessed by total coliforms and mesophillic aerobe counts. The application of this natural antioxidant reduced, in some cases, meat lipidic oxidation, improved its microbiological quality, and did not leave any perceivable residues as analyzed by a sensorial evaluation panel.
\end{abstract}

\section{INTRODUCTION}

During the last few decades, chicken meat has been massively consumed at global level (Magdelaine et al., 2008; Lee et al., 2008; Liu y Niu, 2008), partly due to its excellent nutritional and sensorial qualities. However, depending on the dietary fat source, lipids in meat may be more or less susceptible to oxidation (Grau et al., 2001). Oxidative rancitidy $(\mathrm{OR})$ or lipid oxidation is not only one of the main causes of food spoilage, including chicken meat (Pearson et al., 1977; Sheehy et al., 1993; De Winne \& Dirinck, 1996; Morrisey et al., 1997), but also reduced meat nutritional value due to the loss of important fatty acids, and may pose a health risk to humans resulting from the accumulation of oxidation products (Gray et al., 1996). Moreover, OR has deleterious effects on meat texture, flavor, and color (Gray et al., 1996), affecting its sensorial quality.

This problem may be reduced by including antioxidants (AOX) in broiler feeds (Fellenberg \& Speiski, 2006). The dietary addition of vitamin $\mathrm{E}$ at levels higher than the nutritional requirements (200 ppm) results in higher meat oxidative stability (De Winnie \& Dirink, 1996; Grau et al., 2001), but increases production costs. The dietary inclusion of AOXs of plant origin has also been evaluated (Lopez-Bote et al., 1998; Ruiz et al., 2001; Botsoglu et al., 2004, Fellenberg et al., 2008); however, in addition of increasing feeding costs, the effect on meat oxidative stability have been quite variable. The application of AOXs directly to the meat may prevent meat oxidation, as they would capture compounds that initiate lipid oxidation or stop the chain (Fellenberg \& Speisky, 2006). Synthetic AOXs may used for that purpose, but their application and safety have been questioned (Ito et al., 1983; Ito et al., 1985; Kahl \& Kappus, 1993; Iverson, 1995). Natural AOXs can also 
be used, and their origin provides some guarantee of their safety.

Another cause of chicken meat spoilage is microbial contamination, which can derive from the carcass itself or acquired during processing. Chilling is a mandatory step in the line of broiler carcass processing as it is necessary to lower internal carcass temperature to $4^{\circ} \mathrm{C}$ within the first four hours of slaughter (Dickens \& Ingrams, 2001). In this sense, Pietzsch \& Levertzow (1974) reported that carcasses were washed in the beginning of chilling, but at the end of this stage, carcasses are contaminated with bacteria that remain in the water of the chiller.

Different researchers have studied natural products that could reduce bacterial contamination. For instance, Lis-Balchin et al. (1998), Hao et al. (1998) y Dickens \& Ingram (2001) reported bacterial count reduction in chicken meat treated with different plant extract. It was determined that polyphenols, molecules frequently present in plants, have bactericidal or bacteriostatic effects (Cowan, 1999). Bose (1958) observed that anthemic acid, a phenolic acid extracted from chamomile, had bactericidal effects on $M$. tuberculosis, S. typhimorium y S. aureus, which was later confirmed by Scheel (1972) and Hamburger \& Hostettmann (1991). Moreover, Vijaya et al. (1995) and Toda et al. (1992) found that catechins present in green tea reduced Shigella and Vibrio counts, respectively, and Hunter \& Hull (1993) reported that phloretin, derived from a flavonoid extracted from a wild apple, reduced general bacterial counts.

Quillay (Quillaja saponaria) is a native tree of Chile that is being rationally exploited to obtain saponins, which are used as adjuvants in animal and human vaccines (Wu et al., 1992; Kensil, 1996). One of the byproducts of quillay extraction is a polyphenol mixture that after extraction and purification (QLPerm ${ }^{\circledR}$ ) may have antioxidant and antimicrobial effects. Commercial marination is a process of broiler processing when a solution of water, salt, and other ingredients are added to the meat by immersion, tumbling or injection (Smith \& Acton, 2001), which main objective is to improve meat sensorial characteristics (texture, flavor, tenderness). Therefore, the inclusion of quillay polyphenol extract (which is approved as human food additive by the CODEX ALIMENTARIUS') to chicken meat marinade could improve its oxidative and microbiological quality. The present study aimed at evaluating the effect of the application of a quillay polyphenol extract in chicken meat marinade on meat oxidative rancidity, bacterial count, and sensorial quality.

1 - Quillay extract I y II, SIN numbers 999(i) and 999(ii).

\section{MATERIALS AND METHODS}

\section{Quillay polyphenol extract}

QLPerm $^{\circledR}$, manufactured by a Chilean company, was used. QLPerm ${ }^{\circledR}$ characteristics are shown in Table 1 .

\begin{tabular}{|c|c|}
\hline \multicolumn{2}{|c|}{ QLPerm $\circledast$ characteristics } \\
\hline Polyphenols ${ }^{1}$ & $7.16 \%$ \\
\hline Tannins $^{2}$ & $1.84 \%$ \\
\hline Polysaccharides ${ }^{1,2}$ & $18.60 \%$ \\
\hline CAOX & $\begin{array}{l}70 \% \text { free-radical inhibition using } 0.2 \text { mole of } \\
\text { polyphenol derived from QLPerm }{ }^{\circledast} / \mathrm{mole}^{\mathrm{DPPH}} \text {. } \\
5.21 \mathrm{~g} \text { of the product to inhibit } 75 \% \text { of } 1 \mathrm{mMole} \\
\text { DPPH }\end{array}$ \\
\hline \multicolumn{2}{|c|}{1 - Segarra et al., 1995. 2 - Molina, 2000.} \\
\hline
\end{tabular}

Marination and refrigeration of meat samples

Broilers were slaughtered in a commercial processing plant. Marinade was prepared with the brine solution typically used in the processing plant (phosphates and polyphosphates $60 \%$, salt $27 \%$, carragenin $10 \%$, and guar gum 3\%), to which QLPerm ${ }^{\circledR}$ was added according to the quantities shown in Table 2 . After the solutions were prepared, 60 carcasses per treatment, totaling 300 carcasses, were marinated by injection, with $10 \%$ marinade retention. Carcasses were cut up to obtain breasts and thighs, totaling 120 half breasts and 120 thighs per treatment ( 5 marinade solutions), which were placed in plastic ziploc ${ }^{\circledR}$ bags, and refrigerated at $6^{\circ} \mathrm{C}$ for $0,2,4,6$, or 8 days, with 24 half breasts and 24 deboned thighs per treatment and per refrigeration day. Out of the 24 half breast and 24 thigh samples, 4 were submitted to lipid oxidation analysis, 4 to microbiological analysis, and 16 to sensorial evaluation.

\begin{tabular}{|c|c|c|c|}
\hline \multicolumn{2}{|c|}{ Table 2 - QLPerm ${ }^{\circledR}$ concentration in the marinade brine. } \\
\hline Brine & $\begin{array}{c}\text { QLPerm } \\
\text { (g/100 } \text { addition } \\
\text { solution) }\end{array}$ & $\begin{array}{c}\text { Final concentration } \\
\mathbf{( \% )}\end{array}$ & $\mathbf{p H}$ \\
\hline 1 & 50 & 0.05 & 8.28 \\
\hline 2 & 100 & 0.10 & 8.25 \\
\hline 3 & 150 & 0.15 & 8.23 \\
\hline 4 & 200 & 0.20 & 8.21 \\
\hline Control & 0 & 0.00 & 8.31 \\
\hline
\end{tabular}

Laboratory analyses

Basal lipid oxidation and susceptibility to lipid oxidation

Basal lipid oxidation and susceptibility to lipid oxidation analyses were carried out according to 
Antioxidant and Bacteriostatic Effects of the Addition of Extract of Quillay Polyphenols (Quillaja saponaria) in the Marinade of Broiler Chickens

Fellenberg et al. (2008). Tissue simples weighing $1,000 \mathrm{mg}$ were homogenized with $10 \mathrm{~mL}$ phosphate buffer at $\mathrm{pH}$ 7.4. Total homogenates were divided in two 5 -mL flasks. To one flask, $50 \mu \mathrm{L} \mathrm{FeCl}_{3}$ at $5.05 \mathrm{mM}$ and $50 \mu \mathrm{L}$ buffer to the other. Flasks were incubated for 0 (basal lipid oxidation) and 20min (susceptibility to lipid peroxidation induced by temperature and $\mathrm{Fe}+$ temperature) in water bath $\left(37^{\circ} \mathrm{C}\right)$ with slow agitation. A volume of $600 \mu \mathrm{L}$ total homogenate was added to a tube containing $100 \mu \mathrm{L} \mathrm{TCA}$ at $60 \%$ and EDTA at $2 \mathrm{mM}$, agitated, and centrifuged at $12,000 \times \mathrm{xg}$ for $5 \mathrm{~min}$ at $24^{\circ} \mathrm{C}$. Then, $500 \mu \mathrm{L}$ of the supernatant was mixed with $1,000 \mu \mathrm{L}$ thiobarbituric acid (TBA-Sigma) at $0.67 \%$ in $\mathrm{HCl}$ at $0.3 \mathrm{M}$, incubated in water at $100^{\circ} \mathrm{C}$ for $10 \mathrm{~min}$, and the absorbance was read at $535 \mathrm{~nm}$. Results were expressed as absorbance at $535 \mathrm{~nm} / \mathrm{g}$ tissue.

\section{Mesophilic aerobe count (MAC) and total coliform count (TC)}

Ten g were taken from each sample, added to $90 \mathrm{~mL}$ peptone water at $0.1 \%$ (Oxoid), and homogenized for $2 \mathrm{~min}$, and then were submitted to serial dilutions. The Petrifilm 3M technique (Blackburn et al., 1996) was used for mesophilic aerobe and total coliform counts. All samples were analyzed in duplicate.

\section{Sensorial evaluation}

Sensorial evaluation was carried out by the Tasting Panel of the Department of Agroindustry and Enology of the University of Chile. Quality parameters were evaluated by a descriptive method with 12 trained evaluators (Watts et al., 1992), utilizing a 0 - to $15 \mathrm{~cm}$ non-structured scale. Appearance, color, lightness, and aroma were evaluated in raw meat, and appearance, flavor and aroma in cooked meat (Pedrero \& Pangborn, 1989; Watts et al., 1992). Acceptability was measured by the hedonic scale method (Watts et al., 1992) using a a 0 - to $15 \mathrm{~cm}$ non-structured scale and 24 evaluators. The sensorial evaluation was carried out in a properly equipped room, with individual boots, positive air pressure, and red light to mask color differences.

\section{Statistical analysis}

A completely randomized experimental design was applied, with five level for each factor, determining a 5*5 factorial arrangement (5 AOX inclusion levels * 5 refrigeration periods). Three replicates for each combination of levels were considered. Means were compared by the test of Tukey at each refrigeration level when interactions were significant. If no interaction was significant, the increasing AOX concentration level within the mean response to refrigeration level was evaluated.

\section{RESULTS}

\section{Lipid oxidation}

Breast meat. Basal lipid oxidation increased with refrigeration time and was lower in the meat marinated with QLPerm $^{\circledast}$ (Table 3). There was no protective effect of QLPerm ${ }^{\circledR}$ against lipid oxidation induced by incubation at $37^{\circ} \mathrm{C}$. When lipid oxidation was induced by incubation at $37^{\circ} \mathrm{C}$ plus Fe addition, the interaction between factors was significant. At refrigeration days 0 and 4, the meat marinated with the three lowest doses of QLPerm ${ }^{\circledast}$ showed lower lipid oxidation than the control meat, whereas at refrigeration day 2 , the meat marinated with 0.1 and $0.15 \%$ QLPerm $^{\circledR}$ presented lower lipid oxidation than the control meat.

On refrigeration day 8 , there were no significant differences between the control treatment and the breast meat which marinade included quillay extract.

Thighs. There were no significant differences among treatments as to basal lipid oxidation. When lipid oxidation was induced by temperature, there was interaction between factors. In this case, TBARS were lower in the meat with QLPerm ${ }^{\circledR}$ at refrigeration day $6\left(0.05 \%\right.$ QLPerm $\left.{ }^{\circledast}\right)$, refrigeration days 2 and $6(0.1 \%$ QLPerm $\left.^{\oplus}\right)$, and refrigeration day $4(0.15$ and $0.2 \%$ QLPerm ${ }^{\circledR}$ ). When lipid oxidation was induced by $\mathrm{Fe}$ and temperature, the meat marinated with the control brine presented lower TBARS concentrations than those marinated with QLPerm ${ }^{\circledR}$.

\section{Microbiology}

MAC (Figure 1) was lower in at least one order of magnitude in the meat marinated with QLPerm ${ }^{\circledR}$ as compared to the meat marinated in traditional brine, and similar in all meats marinated up to four days of refrigeration, after which, the difference between meats marinated in the control brine or with QLPerm ${ }^{\circledR}$.

TC (Figure 2) in thigh and breast meat was also lower in the meat marinated with QLPerm ${ }^{\circledR}$.

\section{Sensorial evaluation}

The quality parameters appearance, color, lightness, and aroma were not different between raw meats marinated with QLPerm ${ }^{\circledR}$ or control marinade (Table 5). However, in cooked breast, aroma was considered better in the meat marinated with QLPerm ${ }^{\circledR}$ than that marinated in the control brine. Acceptability of 
Table 3 - Lipid oxidation in chicken breast.

\begin{tabular}{|c|c|c|c|c|c|c|}
\hline \multicolumn{6}{|c|}{$\mathrm{DO} / \mathrm{g}$ tissue } & \multirow[b]{3}{*}{ Mean } \\
\hline & \multicolumn{5}{|c|}{ Concentration (\%) } & \\
\hline Refrig. (days) & 0 & 0.05 & 0.1 & 0.15 & 0.2 & \\
\hline \multicolumn{7}{|c|}{ A.- Basal lipid oxidation } \\
\hline 0 & 0.085 & 0.018 & 0.035 & 0.020 & 0.042 & 0.040 \\
\hline 2 & 0.110 & 0.029 & 0.040 & 0.038 & 0.076 & 0.058 \\
\hline 4 & 0.113 & 0.062 & 0.040 & 0.053 & 0.064 & 0.066 \\
\hline 6 & 0.144 & 0.070 & 0.047 & 0.060 & 0.102 & 0.084 \\
\hline 8 & 0.106 & 0.096 & 0.120 & 0.055 & 0.083 & 0.091 \\
\hline Mean & $0.112 \mathrm{~A}$ & $0.055 B$ & $0.056 \mathrm{~B}$ & $0.045 B$ & $0.074 \mathrm{~B}$ & \\
\hline \multicolumn{7}{|c|}{ B,- Lipid oxidation induced by incubation at $37^{\circ} \mathrm{C}$ for $20 \mathrm{~min}$} \\
\hline 0 & 0.077 & 0.040 & 0.060 & 0.034 & 0.051 & 0.052 \\
\hline 2 & 0.119 & 0.107 & 0.093 & 0.060 & 0.178 & 0.111 \\
\hline 4 & 0.117 & 0.087 & 0.065 & 0.097 & 0.103 & 0.093 \\
\hline 6 & 0.083 & 0.064 & 0.065 & 0.075 & 0.052 & 0.067 \\
\hline 8 & 0.158 & 0.141 & 0.094 & 0.107 & 0.096 & 0.119 \\
\hline Mean & $0.111^{\mathrm{A}}$ & $0.088^{\mathrm{A}}$ & $0.075^{\mathrm{A}}$ & $0.075^{\mathrm{A}}$ & $0.096^{\mathrm{A}}$ & \\
\hline \multicolumn{7}{|c|}{$\mathrm{C}$ - - Lipid oxidation induced by incubation at $37^{\circ} \mathrm{C}$ for $20 \mathrm{~min}$ and addition of $\mathrm{FeCl}_{3}$} \\
\hline 0 & $2.427^{\mathrm{A}}$ & $0.205^{\mathrm{B}}$ & $0.320^{B}$ & $0.323^{B}$ & $0.348^{B}$ & 0.725 \\
\hline 2 & $1.669^{\mathrm{A}}$ & $1.395^{A B}$ & $0.410^{B}$ & $0.460^{B}$ & $2.179^{\mathrm{A}}$ & 1.223 \\
\hline 4 & $0.967^{\mathrm{A}}$ & $0.127^{\text {B }}$ & $0.203^{\text {B }}$ & $0.415^{\mathrm{B}}$ & $0.578^{A B}$ & 0.458 \\
\hline 6 & $0.129^{B}$ & $0.101^{B}$ & $0.133^{B}$ & $0.103^{B}$ & $1.024^{\mathrm{A}}$ & 0.298 \\
\hline 8 & $0.354^{A}$ & $0.189^{A}$ & $0.071^{A}$ & $0.165^{\mathrm{A}}$ & $0.140^{A}$ & 0.184 \\
\hline Mean & 1.109 & 0.403 & 0.227 & 0.293 & 0.854 & \\
\hline
\end{tabular}
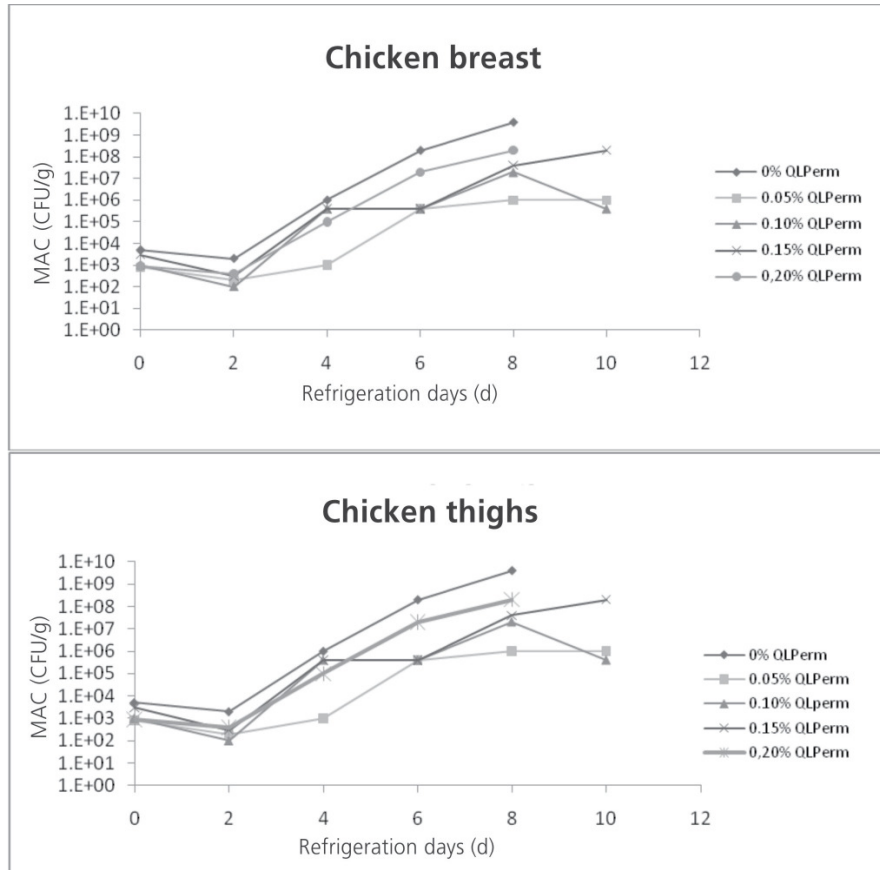

Figure 1 - Mesophilic aerobe count in the breast meat and thigh meat of chicken carcasses marinated with different QLPerm ${ }^{\circledR}$ concentrations.
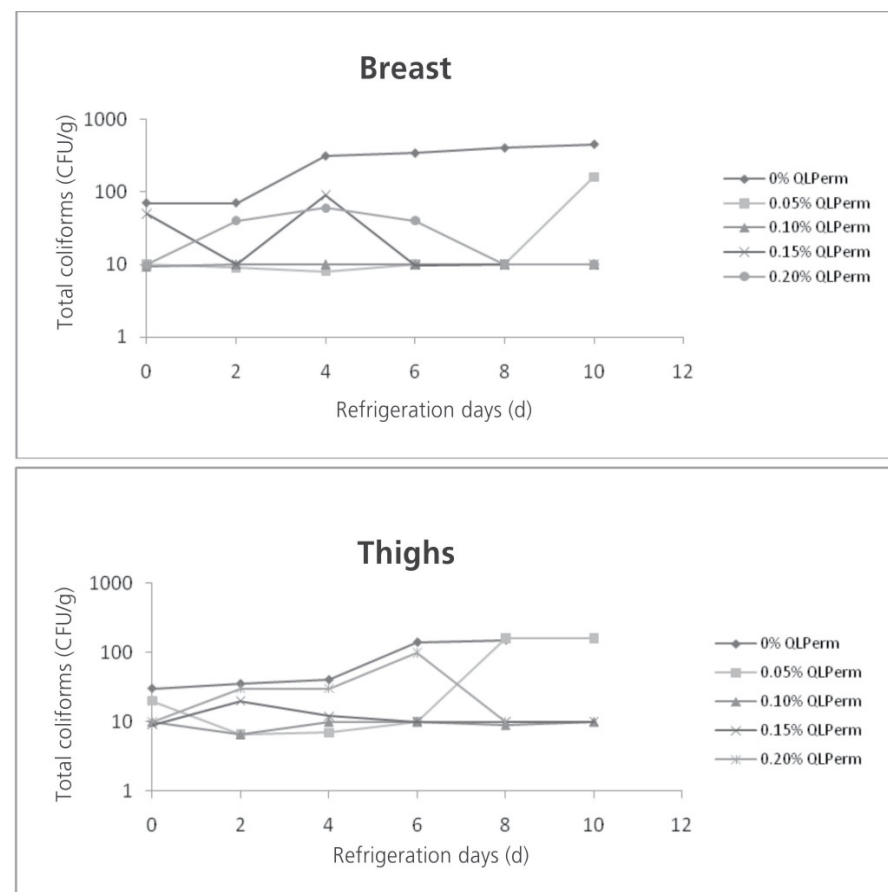

Figure 2 - Total coliform count in the breast meat and thigh meat of chicken carcasses marinated with different QLPerm $^{\circledR}$ concentrations. 
Table 4 - Lipid oxidation in chicken thighs.

\begin{tabular}{|c|c|c|c|c|c|c|}
\hline & \multicolumn{5}{|c|}{$\mathrm{DO} / \mathrm{g}$ tissue } & \\
\hline & \multicolumn{5}{|c|}{ Concentration (\%) } & \\
\hline \multicolumn{7}{|c|}{ A.- Basal lipid oxidation } \\
\hline Refrig. (days) & 0 & 0.05 & 0.1 & 0.15 & 0.2 & Mean \\
\hline 0 & 0.056 & 0.021 & 0.039 & 0.037 & 0.053 & 0.041 \\
\hline 2 & 0.147 & 0.068 & 0.053 & 0.077 & 0.112 & 0.091 \\
\hline 4 & 0.092 & 0.135 & 0.087 & 0.089 & 0.083 & 0.097 \\
\hline 6 & 0.187 & 0.082 & 0.319 & 0.166 & 0.258 & 0.202 \\
\hline 8 & 0.220 & 0.208 & 0.336 & 0.136 & 0.280 & 0.236 \\
\hline Mean & $0.140^{\mathrm{A}}$ & $0.103^{\mathrm{A}}$ & $0.167^{\mathrm{A}}$ & $0.101^{\mathrm{A}}$ & $0.157^{\mathrm{A}}$ & \\
\hline \multicolumn{7}{|c|}{ B.- Lipid oxidation induced by incubation at $37^{\circ} \mathrm{C}$ for $20 \mathrm{~min}$} \\
\hline 0 & $0.149^{A}$ & $0.029^{A}$ & $0.047^{\mathrm{A}}$ & $0.077^{\mathrm{A}}$ & $0.072^{A}$ & 0.075 \\
\hline 2 & $0.426^{\mathrm{A}}$ & $0.171 \mathrm{AB}$ & $0.095^{\mathrm{B}}$ & $0.226^{\mathrm{AB}}$ & $0.355^{\mathrm{AB}}$ & 0.255 \\
\hline 4 & $0.450^{\mathrm{A}}$ & $0.168^{\mathrm{AB}}$ & $0.209^{A B}$ & $0.102 \mathrm{~B}$ & $0.091^{\text {в }}$ & 0.204 \\
\hline 6 & $0.849^{A}$ & $0.105^{c}$ & $0.485^{\mathrm{B}}$ & $0.245^{B C}$ & $0.311^{\mathrm{BC}}$ & 0.399 \\
\hline 8 & $0.316^{\mathrm{A}}$ & $0.316^{\mathrm{A}}$ & $0.222^{\mathrm{A}}$ & $0.195^{\mathrm{A}}$ & $0.385^{\mathrm{A}}$ & 0.287 \\
\hline Mean & 0.438 & 0.158 & 0.212 & 0.169 & 0.243 & \\
\hline \multicolumn{7}{|c|}{ C.- Lipid oxidation induced by incubation at $37^{\circ} \mathrm{C}$ for $20 \mathrm{~min}$ and addition of $\mathrm{FeCl}_{3}$} \\
\hline 0 & 0.594 & 0.043 & 0.185 & 0.263 & 0.223 & 0.261 \\
\hline 2 & 1.031 & 0.534 & 0.213 & 0.537 & 0.816 & 0.626 \\
\hline 4 & 0.388 & 0.210 & 0.094 & 0.160 & 0.210 & 0.212 \\
\hline 6 & 1.073 & 0.162 & 0.523 & 0.276 & 0.613 & 0.529 \\
\hline 8 & 0.779 & 0.382 & 0.613 & 0.329 & 0.654 & 0.551 \\
\hline Mean & $0.773^{A}$ & $0.266^{B}$ & $0.326^{\mathrm{B}}$ & $0.313^{\mathrm{B}}$ & $0.503^{\mathrm{B}}$ & \\
\hline
\end{tabular}

\begin{tabular}{|c|c|c|c|c|c|}
\hline \multirow[b]{2}{*}{ Quality attribute } & \multirow{2}{*}{ Control } & \multicolumn{4}{|c|}{ QLPerm (\%) } \\
\hline & & 0.05 & 0.1 & 0.15 & 0.2 \\
\hline \multicolumn{6}{|l|}{ Raw breast meat } \\
\hline \begin{tabular}{|l} 
Appearance \\
\end{tabular} & $10.79^{A}$ & $10.30^{\mathrm{A}}$ & $10.62^{A}$ & $10.40^{\mathrm{A}}$ & $10.31^{\mathrm{A}}$ \\
\hline Color & $7.63^{A}$ & $7.87^{\mathrm{A}}$ & $8.07^{\mathrm{A}}$ & $7.60^{\mathrm{A}}$ & $7.85^{\mathrm{A}}$ \\
\hline Lightness & $8.60 \mathrm{AB}$ & $8.14^{\mathrm{B}}$ & $8.81^{\mathrm{A}}$ & $8.56 \mathrm{AB}$ & $8.74^{\mathrm{A}}$ \\
\hline Aroma & $7.04^{\mathrm{A}}$ & $6.75^{\mathrm{A}}$ & $6.83^{\mathrm{A}}$ & $7.19^{\mathrm{A}}$ & $6.98^{\mathrm{A}}$ \\
\hline \multicolumn{6}{|c|}{ Cooked breast meat } \\
\hline Appearance & $10.71^{\mathrm{A}}$ & $10.71^{\mathrm{A}}$ & $9.87^{\mathrm{A}}$ & $10.87^{A}$ & $10.91^{\mathrm{A}}$ \\
\hline Flavor & $7.72{ }^{A}$ & $7.76^{\mathrm{A}}$ & $7.66^{A}$ & $7.95^{\mathrm{A}}$ & $7.71^{\mathrm{A}}$ \\
\hline Aroma & $7.88^{A}$ & $7.32^{\mathrm{B}}$ & $7.17^{\mathrm{B}}$ & $7.56 \mathrm{AB}$ & $6.97^{\mathrm{B}}$ \\
\hline \multicolumn{6}{|l|}{ Raw thigh meat } \\
\hline Appearance & $9.64^{\mathrm{A}}$ & $9.17^{\mathrm{A}}$ & $9.06^{\mathrm{A}}$ & $9.33^{\mathrm{A}}$ & $8.56^{\mathrm{B}}$ \\
\hline Color & $7.80^{\mathrm{A}}$ & $7.81^{\mathrm{A}}$ & $7.70^{\mathrm{A}}$ & $7.97^{\mathrm{A}}$ & $7.88^{\mathrm{A}}$ \\
\hline Lightness & $8.48^{\mathrm{A}}$ & $8.01^{\mathrm{A}}$ & $8.36^{\mathrm{A}}$ & $8.26^{\mathrm{A}}$ & $8.19^{\mathrm{A}}$ \\
\hline Aroma & $6.04^{\mathrm{A}}$ & $6.05^{\mathrm{A}}$ & $6.37^{\mathrm{A}}$ & $6.60^{A}$ & $6.71^{\mathrm{A}}$ \\
\hline \multicolumn{6}{|l|}{\begin{tabular}{|l|} 
Cooked thigh meat \\
\end{tabular}} \\
\hline Appearance & $9.16^{\mathrm{A}}$ & $9.22^{\mathrm{A}}$ & $9.72^{\mathrm{A}}$ & $9.39^{A}$ & $9.64^{\mathrm{A}}$ \\
\hline \begin{tabular}{|l} 
Flavor \\
\end{tabular} & $7.66^{\mathrm{A}}$ & $7.66^{\mathrm{A}}$ & $7.73^{\mathrm{A}}$ & $7.34^{\mathrm{A}}$ & $7.76^{\mathrm{A}}$ \\
\hline Aroma & $7.14^{\mathrm{A}}$ & $7.08^{A}$ & $6.89^{A}$ & $7.07^{\mathrm{A}}$ & $7.22^{\mathrm{A}}$ \\
\hline
\end{tabular}


Table 5B - Sensorial evaluation: Acceptability.

\begin{tabular}{|l|c|c|c|c|c|}
\hline & \multirow{2}{*}{ Control } & \multicolumn{4}{|c|}{ QLPerm (\%) } \\
\cline { 3 - 6 } & & $\mathbf{0 . 0 5}$ & $\mathbf{0 . 1}$ & $\mathbf{0 . 1 5}$ & $\mathbf{0 . 2}$ \\
\hline Cooked breast & $8.89 \mathrm{~A}$ & $9.22^{\mathrm{A}}$ & $9.02^{\mathrm{A}}$ & $8.66^{\mathrm{A}}$ & $8.89^{\mathrm{A}}$ \\
\hline Cooked thighs & $8.25 \mathrm{~A}$ & $8.48^{\mathrm{A}}$ & $8.56^{\mathrm{A}}$ & $8.56^{\mathrm{A}}$ & $8.17^{\mathrm{A}}$ \\
\hline
\end{tabular}

$A, B, C$ - Differences among treatments (columns) $(p<0.05)$. Each result is the average of three samples.

the thighs and breasts marinated with QLPerm ${ }^{\circledR}$ was also better than those marinated in the control brine, although not statistically significant.

\section{DISCUSSION}

The analysis of basal lipid oxidation shows the degree of oxidation of meat lipids until this process is reduced by sample freezing. Both basal lipid oxidation and lipid oxidation induced by temperature were significantly higher in the thighs as compared to the breast, and the magnitude of the difference was lower at some refrigeration times. The higher lipid oxidation in thighs is due to the fact that its lipid content is higher than in breasts, relatively providing more substrate that can be oxidized (Pikul et al., 1985; Salih et al., 1989; Liu \& Niu, 2008). Moreover, thighs, as compared to breast meat, are rich in inorganic iron and heme proteins (Johns et al., 1989; Monahan et al., 1993), which catalyze lipid oxidation. On the other hand, when lipid oxidation was induced by Fe and temperature, statistical differences were observed relative to the control treatment at refrigeration days 2,4 , and 6 , and in two concentrations on this day $(0.1$ and $0.2 \%)$. The other refrigeration times and quillay extract concentrations did not affect the lipid oxidation of meats induced by Fe and temperature. It is possible that, when Fe was added as an inducer of lipid oxidation, Fe levels became similar in the thigh and the breast. These results indicate the tissue Fe content may be more relevant than lipid content for the occurrence of lipid oxidation.

In the breast marinated with QLPerm ${ }^{\circledR}$, basal lipid oxidation was significantly lower than that marinated with the control brine. No statistical differences were obtained in the thighs.

As to lipid oxidation induced by temperature, breast meat marinated with QLPerm ${ }^{\circledR}$ was not different from the control meat. Thigh meat presented mixed results, which did not allow us to conclude of the application of QLPerm ${ }^{\circledR}$ in the marinade effectively protected this meat against this type of induced lipid oxidation.

On the other hand, lipid oxidation induced by the addition of $\mathrm{Fe}$ and incubation at $37{ }^{\circ} \mathrm{C}$ is the most challenging for the antioxidant product, as the meat sample is submitted to highly pro-oxidative conditions. In the case of thigh meat, the addition of QLPerm ${ }^{\circledR}$ to the marinade protected this meat against induced lipid oxidation. In breast meat, protection occurred on refrigeration day 0 for all application levels, refrigeration day 2 (0.1 and $0.15 \%$ QLPerm $^{\circledR}$ application), and refrigeration days 4 and 6 for the three lower doses. On refrigeration days 6 and 8, lipid oxidation of the control meat was reduced, reaching statistically similar levels as those of the meat marinated with quillay extract. Although this result was not expected, as oxidation usually increases with storage time, it is possible that, during storage, all substrate required for this evaluation was spent.

There is little information on the effect of the inclusion on natural $A O X$ in the marinade of different meats. Nevertheless, these results partially agree with the findings of Mielnik et al. (2008), who evaluated the effect of the incorporation of rosemary, sage, and thyme in turkey thighs, and reported that these antioxidant plant extracts reduced meat TBARS content when added to the marinade as compared to the control meat. McKenna et al. (2003) showed that lamb marinated with cranberry and onion oleoresins, black pepper, and rosemary reduced meat lipid oxidation. On the other hand, it was reported that accumulation of heterocyclic amines in meat at the time of heat treatment is related to the presence of free radicals (Skog et al., 1998; Arvidsson et al., 1999; Skog et al., 2000). In this sense, Busquets et al. (2006) and Melo et al. (2008) mentioned that the incorporation of red wine and red wine and beer, respectively, reduce the accumulation of heterocyclic amines in fried chicken breast and fried beef. The attenuation or reduction of the effect of free radicals on meat systems by reducing lipid oxidation or the production of heterocyclic amines is essential for human health, as well as for preventing the sensorial deterioration caused by these processes. As previously mentioned, information on the effect of natural AOXs included in chicken meat marinades is lacking, warranting further research on their true protective effects.

It is known that polyphenols can act as antioxidants or pro-oxidants, depending on their concentration and interactions with the food matrix (Melo et al., 2008). Interestingly, in the three lipid oxidation analyses carried out in the present study, the highest QLPerm ${ }^{\circledR}$ inclusion level did not always present antioxidative characteristics, and in some situations, was shown to 
be a pro-oxidant (induced lipid oxidation of breast meat at refrigeration days 2 and 6). Botsoglou et al. (2004) observed that the application of dehydrated tomato powder to broiler feeds had a clear antioxidant effect in low doses, but was pro-oxidative at the highest inclusion level. Therefore, further investigations are required to determine if inclusion levels higher than $0.20 \%$ could have this effect in chicken meat.

It is well known that polyphenols present in some plant extract may have some action against microbial growth (Cowan, 1999; Draughon, 2004). It was shown that flavonoids present in green tea negatively affect bacterial growth (Toda et al., 1992; Vijaya et al., 1995), that wine phenolic component reduce Listeria monocitogenes growth (Wen et al., 2003; RodríguezVaquero et al., 2007), and that a polyphenol extract of Geranium sanguineum inhibited the in vitro and in vivo replication of the H7N1 influenza virus (Serkedjieva, 2003).

Under the experimental conditions of the present study, the application of QLPerm ${ }^{\circledR}$ at all levels (0.05$0.2 \%)$ to the marinade of broiler meat reduced in at least one order of magnitude MAC and TC count at some levels. This is consistent with the results of Dickens et al. (2000) and Dickens \& Ingram (2001), who reported that a plant extract added to the chiller water in broiler processing significantly reduced the counts of mesophilic aerobes, total coliforms, E. coli, and Campilobacter.

Although polyphenols and their modes of action are still under investigation, some mechanisms of their biocidal or biostatic effects have been elucidated. It was reported that epicatechin (Toda et al., 1992) and cinnamic acid (Fernández et al., 1996) act by disrupting microbial cell membrane, some flavones inactive enzymes (Brinkworth et al., 1992), whereas some tannins bind proteins (Stern et al., 1996) or inhibit enzymes (Haslam, 1996). Michalczyk \& Zawislak (2008) attempted to relate the antimicrobial activities of tea polyphenols to their antioxidant capacity, but concluded that there was no correlation of these activities in the evaluated green tea, black tea, and puerh. Further research is hended to effectively prove that quillay polyphenols indeed have this microbiological effect and to establish the mode of action.

One of the risks of adding additives to chicken meat marinades is that those may result in aromas or flavors that are not characteristic of chicken meat. Sensorial evaluation is considered an adequate method to perceive these differences. In the present study, the application of QLPerm ${ }^{\circledast}$ did not generate any unpleasant aromas or flavors, as perceived by the sensorial evaluation panel. In fact, appearance, color, aroma, and lightness were considered similar in QLPerm ${ }^{\circledR}$-marinated meat and control meat. This is interesting, as it means that the extract does not leave any residues that may be rejected by future consumers. These results are different from those reported by Mielnik et al. (2008), who marinated turkey meat with rosemary, sage, and thyme extracts and reported that an aroma of spices was perceived.

Under the above-described experimental conditions, quillay polyphenol extract reduced basal lipid oxidation of the breast meat of broilers and lipid oxidation induced by $\mathrm{Fe}$ and incubation at $37{ }^{\circ} \mathrm{C}$ of thigh meat. Lipid oxidation induced by incubation was reduced in three application levels $(0.05,0.1,0.15)$ until refrigeration day 4 in thigh meat. Although these results indicate that quillay extract provided the meat with some protection against oxidation, further studies are required to prove this effect. The microbiological analyses (MAC and TC) suggest that quillay extract has a bacteriostatic effect as meat samples marinated at all application doses presented reduction of 1 to 2 orders of magnitude for MAC and of 1 order of magnitude for TC. Quillay extract did not leave perceivable residues in the meat, as flavor and aroma were considered normal by the sensorial evaluation panel. In the present study, the antioxidative effect of quillay extract was not compared with other natural antioxidants, and therefore, further investigation is warranted to evaluate its real contribution as antioxidant and to compare with other natural antioxidants.

\section{REFERENCES}

Arvidsson P, Van Boekel MAJS, Skog K, Solyakov A, Jägerstad M. Formation of heterocyclic amines in a meat juice model system. Journal of Food Science 1999; 64(2):216-221.

Blackburn CW, Baylis CL, Pettit SB. Evaluation of Petrifilm ${ }^{\mathrm{TM}}$ methods for enumeration of aerobic flora and coliforms in a wide range of foods. Letters in Applied Microbiology 1996; 22(2):137140.

Bose PK. On some biochemical properties of natural coumarins. Journal of the Indian Chemical Society 1958; 58:367-375.

Botsoglou N, Papagergiou G, Nikolakakis I, Florou-Paneri P, Giannenas I, Dotas V, Sinapsis E. Effect of dietary dried tomato pulp on oxidative stability of Japanese quail meat. Journal of Agricultural and Food Chemistry 2004; 52(10):2982-2988.

Brinkworth RI, Stoermer MJ, Fairlie DP. Flavones are inhibitors of HIV-1 proteinase. Biochemical and Biophysical Research Communications 1992; 188(2):631-637. 
Busquets R, Puignou LL, Galceran MT, Skorg K. Effect of red wine marinades on the formation of heterocyclic amines in fried chicken breast. Journal of Agricultural and Food Chemistry 2006; 54(21):8376-8384.

Cowan MM. Plant products as antimicrobial agents. Clinical Microbiology Reviews 1999; 12(4):564-582.

De Winnie A, Dirinck P. Studies on vitamin E and meat quality.2. Effect of feeding high vitamin $E$ levels on chicken meat quality. Journal of Agricultural and Food Chemistry 1996; 44(7):16911696

Dickens JA, Berrang ME, Cox NA. Efficacy of an herbal extract on the microbiological quality of broiler carcasses during a simulated chill. Poultry Science 2000; 79(8):1200-1203.

Dickens JA, Ingram KD. Efficacy of an herbal extract, at various concentrations, on the microbiological quality of broiler carcasses after simulated chilling. The Journal of Applied Poultry Research 2001; 10(2):194-198.

Draughon FA. Use of botanicals as biopreservatives in foods. Food Technology 2004; 58(2):20-28.

Fellenberg MA, Speisky $H$. Antioxidants: their effects on broiler oxidative stress and its meat oxidative stability. World's Poultry Science Journal 2006; 62(1):53-70.

Fellenberg MA, Delporte C, Backhouse N, Peña I, Speisky $H$. Effect of dried extract of boldo Peumus boldus Mol. on growth and oxidative tissue status of broiler chickens. Brazilian Journal of Poultry Science 2008; 10(4): 245-252

Fernandez MA, Garcia MD, Saenz MT. Antibacterial activity of phenolic acid fraction of Scrophularia frutescens and Scrophularia sambucifolia. Journal of Ethnopharmacologie 1996; 53(1):11-14.

Grau A, Guardiola F, Grimpa S, Barroeta AC, Codony R. Oxidative stability of dark chicken meat through frozen storage: influence of dietary fat and alpha-tocopherol and ascorbic acid supplementation. Poultry Science 2001; 80(11):1630-1642.

Gray JI, Gomaa EA, Buckley DJ. Oxidative quality and shelf life of meats. Meat Science 1996; 43(1):111S-123S.

Hamburger $\mathrm{H}$, Hostettmann $\mathrm{K}$. The link between phytochemistry and medicine. Phytochemistry 1991; 30(12):3864-3874.

Hao YY, Brackett RE, Doyle MP. Efficacy of plant extract in inhibiting Aeromonas hydrophila and Listeria monocytogenes in refrigerated, cocked poultry. Food Microbiology 1998; 15(4):367-378.

Haslam E. Natural polyphenols (Vegetable Tannins) as drugs: possible modes of action. Journal of Natural Products 1996; 59(2):205-215.

Hunter MD, Hull LA. Variation in concentrations of phloridzin and phloretin in apple foliage. Phytochemistry 1993; 34(5):1251-1254.

Ito N, Fukushima S, Hagiwara A, Shibata M, Omiso T. Carcinogenicity of butylated hydroxyanisole in F344 rats. Journal of the National Cancer Institute 1983; 70:343-352.
Ito N, Fukushima S, Tsuda H.Carcinogenicity and modification of the carcinogenic response by $\mathrm{BHA}, \mathrm{BHT}$, and other antioxidants. Critical Reviews in Toxicology 1985; 15(2):109-150.

Iverson F. Phenolic antioxidants: health protection branch studies on butylated hydroxyanisole. Cancer Letter 1995; 93(1):49-54.

Johns AM, Birkinshaw LH, Ledward DA. Catalysts of lipid oxidation in meat products. Meat Science 1989; 25(3):209-220.

Kahl R, Kappus $H$. Toxicology of the synthetic antioxidants BHA and $\mathrm{BHT}$ in comparison with the natural antioxidant vitamin $\mathrm{E}$. Zeitschrift für Lebensmittel-Untersuchung und -Forschung 1993; 196:329-338

Kensil CR. Saponins as vaccine adjuvants. Critical Reviews in Therapeutic Drug Carrier Systems 1996; 13(1):1-55.

Lee YS, Owens CM, Meullenet JF. On the Quality of Commercial Boneless Skinless Broiler Breast Meat. Journal of Food Science 2008; 73(6):S253-S261.

Lis-Balchin MG, Buchbauer T, Hirtenlehner T, Resch M. Antimicrobial activity of pelargonium essential oils added to a quiche filling as a model food system. Letters in Applied Microbiology 1998; 27(4):207-210.

Liu F, Niu Z. Carcass Quality of Different Meat - Typed chickens when achieve a common physiological body weight. International Journal of Poultry Science 2008; 7(4):319-322.

Lopez-Bote CJ, Gray JI, Gomaa EA. Flegal CJ. Effect of dietary administration of oil extracts from rosemary and sage on lipid oxidation in broiler meat. British Poultry Science 1998; 39(2):235240.

Magdelaine P, Spiess MP, Valceschini E. Poultry meat consumption trends in Europe. World Poultry Science Journal 2008; 64(1):53-63.

McKenna DR, Strachan DS, Miller RK, Acuff GR, Savell JW. Cranberry juice marinade improves sensory and microbiological properties of vacuum-packaged lamb chops. Journal of Muscle Foods 2003; 14(3):207-220

Melo A, Viegas O, Petisca C, Pinho O, Ferreira I. Effect of beer/red wine marinades on the formation of heterocyclic aromatic amines in pan-fried beef. Journal of Agricultural and Food Chemistry 2008; 56(22):10625-10632.

Mielnik MB, Semb S, Egelandsdal B, Skrede G. By-products from herbs essential oil production as ingredient in marinade for turkey thighs. LWT - Food Science and Technology 2008; 41(1):93-100.

Monahan FJ, Crackel RL, Gray Jl, Buckley DJ, Morrisey PA. Catalysis of lipid oxidation in muscle model systems by haem and inorganic iron. Meat Science 1993; 34(1):95-106.

Molina R. Teoría de la clarificación de mostos y vinos y sus aplicaciones prácticas. Madrid; 2000. p. 265-266.

Morrisey PA, Brandon S, Buckley DJ, Sheey PJA, Frigg M. Tissue content of $\alpha$-tocopheryl acetate supplement for various periods pre-slaughter. British Poultry Science 1997; 38(1):84-88. 
Pearson AM, Love JD, Shorland FB. Warmed over-flavor in meat, poultry and fish. Advances in Food Research 1977; 23(1):1-74.

Pedrero D, Pangborn R. Evaluación sensorial de los alimentos métodos analíticos. México: Ed. Alambra Mexicana; 1989.

Pikul J, Leszczynski DE, Kummerow FA. Influence of fat content and composition on malonaldehyde concentration in chicken meat and skin. Poultry Science 1985; 64(3):311-317

Ruiz JA, Guerrero L, Arnau J, Guardia MD, Esteve-Garcia E. Descriptive sensory analysis of meat from broilers fed diets containing vitamin $\mathrm{E}$ or beta-carotene as antioxidants and different supplemental fats. Poultry Science 2001; 80(7):976-982.

Salih AM, Price JF, Smith DM, Dawson LE. Lipid oxidation in turkey meat as influenced by salt, metal cations and antioxidants. Journal of Food Quality1989; 12(1):71-83

Segarra C. Lao, López-Tamanes E, Torre-Boronat MC de la. Pectrophotometric methods for the anaysis of plysaccharide levels in winemaking products. American Joournal of Enology and Viticulture 1995; 46(4):564-570.

Sheehy PJ, Morrissey PA, Flynn A. Influence of heated vegetable oils and alpha-tocopheryl acetate supplementation on alphatocopherol, fatty acids and lipid peroxidation in chicken muscle. British Poultry Science 1993; 34(2):367-381.

Scheel LD. The biological action of the coumarins. Microbiol Toxins 1972; 88(1):47-66.

Michalczyk M, Zawislak A. The effect of tea infusions on the proliferation of selected bacteria important for the human intestinal tract. Acta Scientarium Polonoum Technologia Alimentaria 2008; $7(1): 59-65$

Smith DP, Acton JC. Marination, cooking, and curing of poultry products. Chapter 15. In: Sams AR, editor. Poultry meat processing. Boca Raton: CRC Press; 2001

Pietzsch O, Levetzow R. The problem of salmonellosis of poultry as related to poultry chilling. Fleischwirtschaft 1974; 54(1):67-78.

Serkedjieva J. Influenza virus variants with reduced susceptibility to inhibition by a polyphenol extract from Geranium sanguineum L. Die Pharmazie 2003; 58(1):53-57.

Skog K, Johansson MA, Jägerstad M. Carcinogenic heterocyclic amines in model systems and cooked foods: a review on formation occurrence and intake. Food and Chemical Toxicology 1998; 64(910):216-221.

Skog K, Solyakov A, Jägerstad M. Effect of heating conditions and additives on the formation of heterocyclic amines with reference to amino-carbolines in a meat juice model system. Food Chemistry 2000; 68(3):299-308

Stern JL, Hagerman AE, Steinberg PD, Mason PK. Phlorotanninprotein interactions. Journal of Chemical Ecology 1996; 22(10): 1877-1899.

Toda M, Okubo S, Ikigai H, Suzuki T, Suzuki Y, Hara Y, Shimamura
T. The protective activity of tea catechins against experimental infections by Vibrio cholerae $\mathrm{O} 1$. Microbiology and Immunology 1992; 36(9):999-1001.

Vijaya K, Ananthan S, Nalini R. Antibacterial effect of theaflavin, polyphenon 60 (Camellia sinensis) and Euphorbia hirta on Shigella spp: a cell culture study. Journal of Ethnopharmacology 1995; 49(2):115-118.

Watts B, Ylimaki G, Jeffery L, Elías L. Métodos básicos para la evaluación de alimentos. Ottawa: Centro Internacional de Investigaciones para el Desarrollo; 1992.

Wu JY, Gardner BH, Murphy CI, Seals JR, Kensil CR, Recchia J, Beltz GA, Newman GW, Newman MJ. Saponin adjuvant enhancement of antigen-specific immune responses to an experimental HIV-1 vaccine. Journal of Immunology 1992; 148(5):1519-1525. 